\title{
Should intracameral triamcinolone acetonide become a mainstay in infantile cataract surgery?
}

\author{
Andrzej Grzybowski ${ }^{1,2}$ (D) Raimo Tuuminen ${ }^{3,4}$ \\ Received: 17 May 2020 / Revised: 17 May 2020 / Accepted: 20 May 2020 / Published online: 28 May 2020 \\ (C) Springer-Verlag GmbH Germany, part of Springer Nature 2020
}

Congenital cataracts are the leading cause of preventable blindness in children [1]. Well-timed surgical intervention may prevent deprivation amblyopia and result in good visual prognosis [2]. Despite advancements in the estimation of refractive outcome, surgical management, and the postoperative control of myopic shift and rehabilitation [3, 4], late adverse events may jeopardize the result of the initial treatment $[5,6]$.

Proper reduction of inflammation is pivotal after pediatric cataract surgery - escpecially in infantile cases - as in these eyes the lack of mature blood-ocular barrier results in intense fibrinous inflammatory response to surgical stimuli $[7,8]$. Postoperative complications arising from intense inflammation include formation of fibrous pupillary membrane, posterior synechiae, and posterior capsule opacifications. Furthermore, surgical management of infantile cases provokes the risk of glaucoma [9].

Reinforced anti-inflammatory medication has become the mainstay of pediatric cataract surgery, yet there is no consensus on which of the anti-inflammatory protocols give desirable efficacy without prohibitively predisposing to the risk of IOP rise. Chou et al. discovered in their meta-analysis that intracameral preservative-free triamcinolone acetonide (TA) reduced the odds ratios for cell deposits, posterior synechias, fibrous anterior chamber reaction, visual axis obscuration, and

Andrzej Grzybowski

ae.grzybowski@gmail.com

1 Department of Ophthalmology, University of Warmia and Mazury, Olsztyn, Poland

2 Institute for Research in Ophthalmology, Foundation for Ophthalmology Development, 60-554 Gorczyczewskiego 2/3, Poznan, Poland

3 Helsinki Retina Research Group, University of Helsinki, Helsinki, Finland

4 Kymenlaakso Central Hospital, Unit of Ophthalmology, Kotka, Finland posterior capsule opacification in non-uveitic pediatric cataracts without any severe ocular adverse events when compared with patients not receiving intracameral TA. Interestingly, the postoperative level of intraocular pressure remained within the physiological range. These favorable outcomes were discussed to arise from dual effects of intracameral TA; both visualization of vitreous body in TAassisted anterior vitrectomy and prolonged anti-inflammatory response. The authors showcase their meticulous approach to the evaluation of the studies chosen, the randomized clinical trials (RCTs) among the others, by employing the Cochrane Collaboration tool, which tends to provide the strong reliability and accuracy of their findings. Any discrepancies on methodological issues were discussed with a third expert. The authors dexterously use the fixed-effects versus the randomeffects meta-analytical models, giving weight to the assessments of heterogeneity and bias.

Without disparaging the merits of the comprehensive metaanalysis, it remains important to acknowledge the several safety aspects missing that need to be addressed before these encouraging findings can be generalized for the purpose of clinical practise recommendations e.g., in Current Care Guidelines. First, it will be important to address the kinetics of IOP within the first postoperative months. Here, the followup focused on IOP at 1 month and beyond 6 months (in two of the studies at 6 months and in three of the studies at 12 months). Within the timeframe, the results indicated recovery from significant IOP rise in the eyes receiving intracameral TA towards the levels of those receiving topical steroids. Second, age is a crucial factor in terms of postoperative inflammatory responses and late adverse events. In this respect, it would be important to stratify the cases according to the age of the patients (for instance from 4 weeks to 6 weeks, 6 weeks to 6 months, 6 months to 2 years, $>2$ years) [10]. Taking into account that four out of five studies concentrated on congenital cataracts and the mean age of intracameral TA recipients ranged between the studies from $2.4 \pm 2.1$ months to $10.45 \pm$ 6.22 months, we can conclude that the majority of the cases 
represent children at preverbal age. Third, discussion on the occurence of late adverse events (i) in relation to TA doses ranging from 1.2 to $2 \mathrm{mg}$ (not available for all the studies) and (ii) between the studies using 2-time and 3-time standardized applications and those administering TA at the end of the surgery may be important viewpoints.

To avoid undesirable secondary interventions in pediatric cataract surgery, a steady and prolonged reinforced antiinflammatory treatment protocol with a proper safety profile is warranted. Multiple steroid delivery methods for adult cataract surgery have been proposed, each one having its advantages and disadvantages [11]. TA is a moderate-strength corticosteroid with a relatively long duration of action. Intraoperative preservative-free TA depot glucocorticoid with insoluble particles is a fascinating alternative to avoid issues of incompliance $[12,13]$. A subconjunctival injection has been shown to result in higher aqueous and vitreous steroid concentrations than eye drops, parabulbar injection, or oral administration $[14,15]$. Unlike with the aforementioned delivery methods or with transzonular injection of compounded formulation, subconjunctival TA administration enables feasible management of a potential steroid-induced IOP rise by surgical excision of the depot [11, 16-19]. Further investigations are needed to optimize the timing, composition, route of delivery, and dosage of anti-inflammatory drug protocols in pediatric cataract surgery.

\section{Compliance with ethical standards}

Conflict of interest The authors declare that they have no conflict of interest.

\section{References}

1. Sheeladevi S, Lawrenson JG, Fielder AR, Suttle CM (2016) Global prevalence of childhood cataract: a systematic review. Eye 30(9): 1160-1169

2. Lambert SR, Cotsonis G, DuBois L, et al. (2020) Long-term effect of intraocular lens vs contact lens correction on visual acuity after cataract surgery during infancy: a randomized clinical trial. JAMA Ophthalmol $2020 \mathrm{Feb} 20$

3. Vanderveen DK, Trivedi RH, Nizam A, Lynn MJ, Lambert SR, Infant Aphakia Treatment Study Group (2013) Predictability of intraocular lens power calculation formulae in infantile eyes with unilateral congenital cataract: results from the Infant Aphakia Treatment Study. Am J Ophthalmol 156(6):1252-1260

4. Weakley DR Jr, Lynn MJ, Dubois L et al (2017) Myopic shift 5 years after intraocular lens implantation in the infant aphakia treatment study. Ophthalmology 124(6):822-827
5. Freedman SF, Lynn MJ, Beck AD et al (2015) Glaucoma-related adverse events in the first 5 years after unilateral cataract removal in the infant aphakia treatment study. JAMA Ophthalmol 133(8):907914

6. Kelly KR, Morale SE, Wang SX, Stager DR, Jr., Birch EE (2019) Impaired fine motor skills in children following extraction of a dense congenital or infantile unilateral cataract. J AAPOS 23(6): 330 e $331-330$

7. Khaja WA, Verma M, Shoss BL, Yen KG (2011) Visual axis opacification in children. Ophthalmology 118(1):224-225

8. Plager DA, Lynn MJ, Buckley EG, Wilson ME, Lambert SR, Infant Aphakia Treatment Study Group (2014) Complications in the first 5 years following cataract surgery in infants with and without intraocular lens implantation in the Infant Aphakia Treatment Study. Am J Ophthalmol 158(5):892-898

9. Vishwanath M, Cheong-Leen R, Taylor D, Russell-Eggitt I, Rahi J (2004) Is early surgery for congenital cataract a risk factor for glaucoma? Br J Ophthalmol 88(7):905-910

10. Birch EE, Wang J, Felius J, Stager DR Jr, Hertle RW (2012) Fixation control and eye alignment in children treated for dense congenital or developmental cataracts. J AAPOS 16(2):156-160

11. Lindstrom RL, Galloway MS, Grzybowski A, Liegner JT (2017) Dropless cataract surgery: an overview. Curr Pharm Des 23(4): 558-564

12. Gills JP, Gills P (2005) Effect of intracameral triamcinolone to control inflammation following cataract surgery. $J$ Cataract Refract Surg 31(8):1670-1671

13. Inatani M, Iwao K, Kawaji T et al (2008) Intraocular pressure elevation after injection of triamcinolone acetonide: a multicenter retrospective case-control study. Am J Ophthalmol 145(4):676-681

14. Weijtens O, Feron EJ, Schoemaker RC et al (1999) High concentration of dexamethasone in aqueous and vitreous after subconjunctival injection. Am J Ophthalmol 128(2):192-197

15. Weijtens O, Schoemaker RC, Romijn FP, Cohen AF, Lentjes EG, van Meurs JC (2002) Intraocular penetration and systemic absorption after topical application of dexamethasone disodium phosphate. Ophthalmology 109(10):1887-1891

16. Kalina PH, Erie JC, Rosenbaum L (1995) Biochemical quantification of triamcinolone in subconjunctival depots. Arch Ophthalmol 113(7):867-869

17. Dieleman M, Wubbels RJ, van Kooten-Noordzij M, de Waard PW (2011) Single perioperative subconjunctival steroid depot versus postoperative steroid eyedrops to prevent intraocular inflammation and macular edema after cataract surgery. J Cataract Refract Surg 37(9):1589-1597

18. Tyson SL, Bailey R, Roman JS, Zhan T, Hark LA, Haller JA (2017) Clinical outcomes after injection of a compounded pharmaceutical for prophylaxis after cataract surgery: a large-scale review. Curr Opin Ophthalmol 28(1):73-80

19. Lindholm JM, Taipale C, Ylinen P, Tuuminen R (2020) Perioperative subconjunctival triamcinolone acetonide injection for prevention of inflammation and macular oedema after cataract surgery. Acta Ophthalmol 98(1):36-42

Publisher's note Springer Nature remains neutral with regard to jurisdictional claims in published maps and institutional affiliations. 